\title{
NOTE ON A MULTI-FREQUENCY AUTOMATIC RECORDER OF IONOSPHERE HEIGHTS ${ }^{1}$
}

\author{
By T. R. Gilliland
}

\section{ABSTRACT}

A system is described which gives a curve of virtual height of the ionosphere against frequency. The pulse method of Breit and Tuve is employed with modifications. Short pulses of radio-frequency energy are transmitted and the time required for the energy to go up and return is recorded automatically by a galvanometer oscillograph of the type previously used for fixed-frequency work. The transmitting and receiving sets are shifted in frequency from 2,500 to 4,400 $\mathrm{kc} / \mathrm{s}$ at the uniform rate of $200 \mathrm{kc} / \mathrm{s}$ per minute.

Records are presented which show the characteristics for different times of day and night. In the daytime, during the period of these tests, three strata were usually indicated. For the lower range of frequencies, reflections come from the $E$ layer with a virtual height of around $120 \mathrm{~km}$. As frequency is increased the waves pass through the $E$ layer and are returned from the $F_{1}$ layer with virtual heights of the order of $200 \mathrm{~km}$. The frequency for which this transition takes place varies with time of day and with season. In the middle of the day, during these tests, this critical frequency was in the neighborhood of $3,000 \mathrm{kc} / \mathrm{s}$, while the critical frequency for passing through the $F_{1}$ to the $F_{2}$ layer was usually between 3,800 and $4,100 \mathrm{kc} / \mathrm{s}$. The $F_{2}$ layer shows virtual heights of $280 \mathrm{~km}$ or more. Of particular interest is the character of the change observed when passing from one stratum to another as the frequency is increased. Although, at times, when passing from $E$ to $F_{1}$ reflections may drop out completely for a short interval, frequently the curve is continuous and the time retardation will reach a high value just before the appearance of the $F_{1}$ reflection. When passing from $F_{1}$ to $F_{2}$ the virtual height frequently reaches 800 or $900 \mathrm{~km}$. As evening approaches reflections no longer come from the $E$ layer for the frequencies $2,500 \mathrm{kc} / \mathrm{s}$ to $4,400 \mathrm{kc} / \mathrm{s}$, and the long retardation between $F_{1}$ and $F_{2}$ becomes less pronounced. By sunset the curve is almost straight and there is little change of height with frequency. Later at night the highest frequencies cease to be returned and long retardations again occur. The phenomenon of double refraction is in evidence at this time.

The system described here offers a more convenient method than the manual methods previously employed and greater economy is obtained in both time and personnel. It is possible to obtain records with much greater detail.

The results are presented with the idea of indicating the value of this method in the study of the physical properties of the upper atmosphere as well as in the study of radio transmission.

\section{CONTENTS}

I. Introduction

II. Description of multi-frequency system

III. Results

IV. Conclusion

1 Presented in part at meeting of American Section, International Scientific Radio Union, at Washington, April 27, 1933, and also presented at Eighth Annual Convention, Institute of Radio Engineers, at Chicago, June 27, 1933. 


\section{INTRODUCTION}

The purpose of this note is to describe a system for automatically recording the virtual heights of the ionized layers of the upper atmosphere for a given band of radio frequencies and to show the type of record obtained. The system utilizes the pulse method of Breit and Tuve ${ }^{2}$ with modifications which permit automatic recording and the shifting of the transmitting and receiving sets continuously over a desired band of frequencies.

Observers in previous work have recorded virtual heights manually where information was desired for more than one frequency. The frequency was varied by steps, and readings of virtual height were made for each step. The disadvantages with this method are that it requires considerable time and labor and, since changes in the ionosphere are often quite rapid, important details are likely to be missed. Critical effects are often observed for very small changes in frequency, so that a system that will give a continuous and rapid frequency variation is desirable.

The importance of the ionosphere in radio transmission has led to an intensive study of its characteristics both in this country and abroad. An investigation which gives fundamental information about its physical properties is of value in the general study of the atmosphere as well as in its application to radio transmission. The system originated by Breit and Tuve for making these studies consists of a radio transmitter, receiving set, and galvanometer oscillograph with photographic attachment. The transmitter is made to send out short pulses, which arrive at the receiving set via the ionosphere as well as by a path along the ground. By passing the output of the receiving set through the oscillograph, a photographic record is made which gives a measure of the time required for the pulse to go up and back. This time interval is used to calculate the "virtual" height.

This method has been modified for automatic recording at a fixed frequency. ${ }^{4}$ This is done by keying the pulses at the transmitter with a chopper driven by a synchronous motor. At the receiving station the oscillograph is provided with a revolving mirror also driven by a synchronous motor connected to the same power system. With this arrangement the pulse pattern is projected onto the oscillograph screen so that the ground-wave pulse remains stationary while the sky-wave pulses shift with respect to it as the virtual height of the ionosphere changes. In order to make a record of the changes taking place, photographic paper is passed over the pulse pattern in a direction parallel to the axis of the revolving mirror. The pattern is masked so that the paper is exposed to only the top portion of the pulses. The usual cylindrical lens of the oscillograph optical system is replaced by a spherical lens so that the light from the top part of the pulse is focused into a small spot on the paper. As the paper moves the ground pulse will trace a straight line since its path length is fixed. As the ionosphere shifts in virtual height, the time required for the other pulses to return will change and traces will be made which vary in distance from the ground trace. This distance gives a direct measure of the virtual height. In the present arrangement

2 Breit and Tuve, Phys. Rev., vol. 21, p. 554, 1926. Proc. I.R.E., vol. 16, p. $1236,1928$.

3 Gilliland and Kenrick, B.S.Jour.Research, vol. 7, p. 783, Nov. 1931; Proc.I.R.E., vol. 20, p. 540, March 1932.

4 Gilliland, B.S.Jour.Research, vol. 11, p. 141, July 1933. 
B.S. Journal of Research, RP608

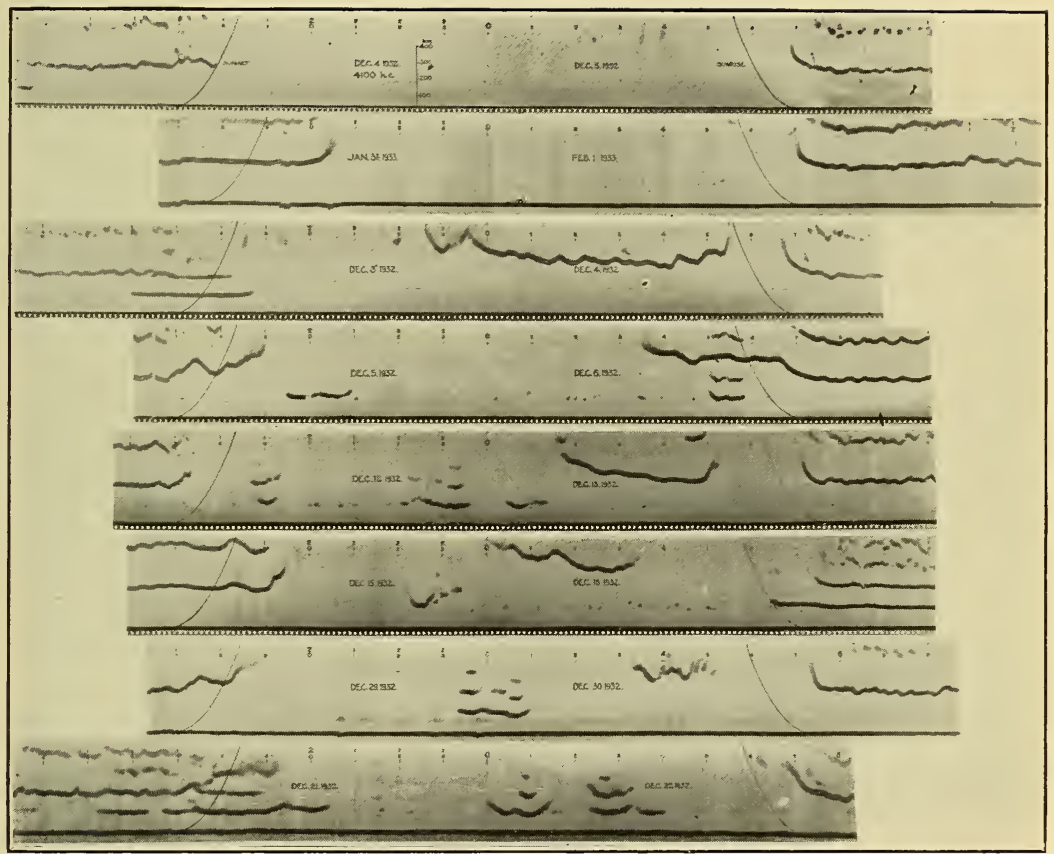

FIGURE 1.-Photograph showing type of record obtained on a fixed frequency of $4,100 \mathrm{kc}$.

The first two records show almost no reflections at night. Third to seventh records, inclusive, show night reflections from both the $\mathrm{E}$ and the $\mathrm{F}$ layers. The last record shows reflections from only the $\mathrm{E}$ layer at night. 
B.S. Journal of Research, RP608

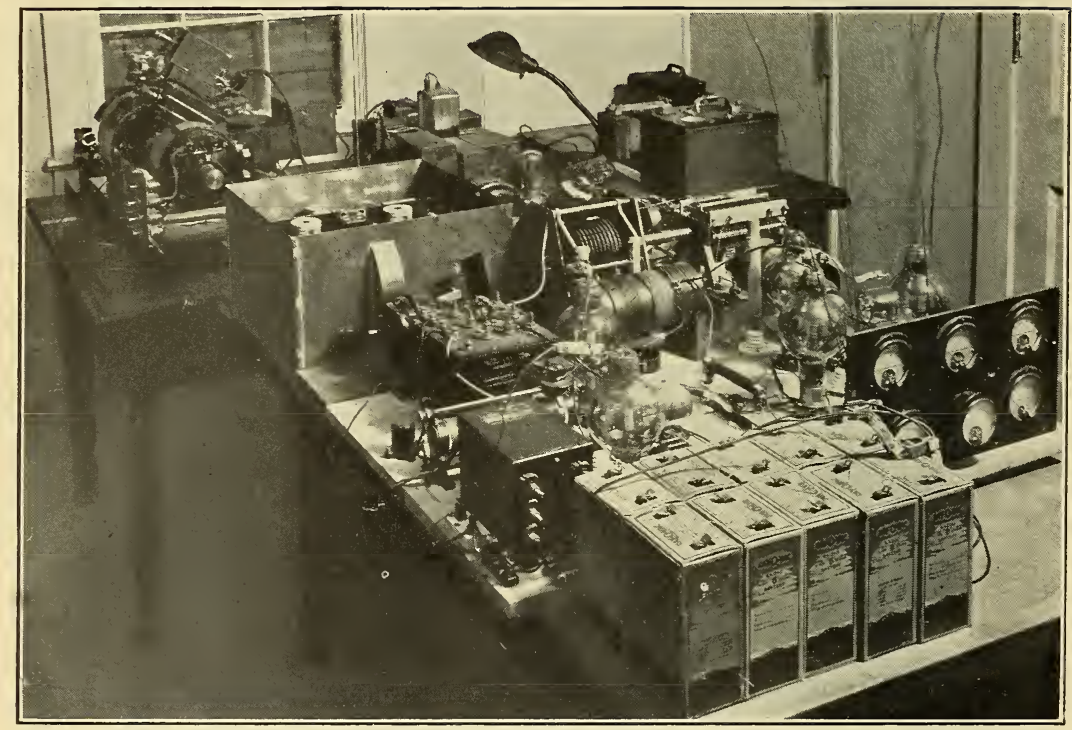

FIGURE 4.-Photograph showing preliminary arrangement.

Transmitter in foreground, receiving set converter in box with cover removed, recorder in background at left. 
the transmitting and receiving sets are placed in the same room and the chopper wheel and revolving mirror are attached to the same shaft. The placing of the complete equipment in one room adds greatly to the simplicity of operation, especially with the multi-frequency system. Troubles from phase shifts in the power system are eliminated.

Figure 1 shows the type of record obtained on eight different days for a fixed frequency of $4,100 \mathrm{kc} / \mathrm{s}$. Here reflections are shown from both the $E$ and the $F$ layers. During the daytime on these days reflections came more often from the $F$ layer showing virtual heights of $240 \mathrm{~km}$ and higher. Reflections from the $E$ region at about 100 to $130 \mathrm{~km}$ were found to occur at irregular intervals. ${ }^{5}$

\section{DESCRIPTION OF MULTI-FREQUENCY SYSTEM}

The recorder for the multi-frequency system is the same as that used for fixed-frequency work. The receiving set is also the same except that a mechanism is introduced for tuning over the desired range of frequencies. A superheterodyne circuit is employed with a broadcast receiving set and high-frequency converter. The galvanometer oscillograph is connected in series with the moving coil of the

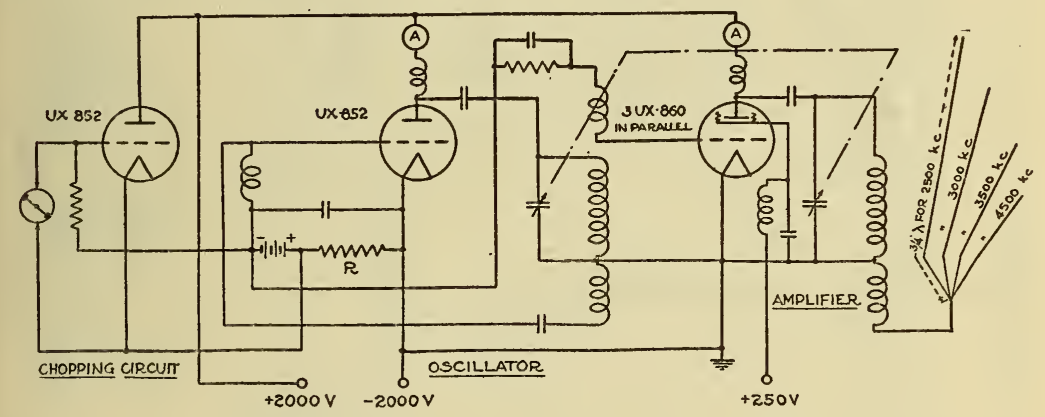

FIGURE 2.-Circuit arrangement of transmitter.

With the chopper contacts open, the oscillator grid is biased below the oscillation condition by the $C$ battery. When the contacts are closed, current flows in the plate circuit of the chopping tube which includes resistance $R$. Current through $R$ brings the oscillator grid up to the oscillation point and at the same time causes the bias on the amplifier grids to assume the proper operating value.

loudspeaker. The circuit arrangement of the transmitter is shown in figure 2. The oscillator circuit using one type UX-852 tube is followed by a single amplifier stage using three type UX-860 tubes in parallel. One UX-852 is employed as a chopping tube to avoid sparking at the chopper contacts which occurs when the oscillator is chopped directly. With the chopper contacts open, the oscillator grid is biased below the oscillation condition by the $C$ battery. When the contacts are closed current flows in the plate circuit of the chopping tube which includes resistance $R$. The current through $R$ brings the oscillator grid up to the oscillation point and at the same time causes the bias on the amplifier grids to assume the proper operating value. The chopper is geared so that about 10 pulses per second are transmitted. The rotors of the oscillator and amplifier tuning condensers are attached to the same shaft.

The antenna system of the transmitter consisted of inverted $L$ antennas of three-fourths wave length for 2,500, 3,000, 3,500, and 
$4,500 \mathrm{kc} / \mathrm{s}$, all connected permanently together at the base. The receiving antenna was a single inverted $L$ of three-fourths wave length for about $4,000 \mathrm{kc} / \mathrm{s}$.

The mechanical arrangement is shown schematically in figure 3 . The transmitter tuning condensers are actuated by one cam while the receiving set condensers are actuated by another. Both cams are attached to a single shaft driven by a synchronous motor through a reduction gear. The cam lever of the transmitter is geared to the condenser shaft by spur gears with a step-up ratio of 4 to 1 so that the rotors turn through $180^{\circ}$ while the cam lever moves through $45^{\circ}$. The rotors of the oscillator and detector tuning condensers of the receiving set are also attached to a single shaft. For the desired range of frequencies these rotors turn through more than $180^{\circ}$ so that a slightly higher gear ratio is used.

It was found that one set of coils of the receiving set could be worked conveniently between $2,500 \mathrm{kc} / \mathrm{s}$ and $4,400 \mathrm{kc} / \mathrm{s}$ without modification and since this is an interesting range for daytime work, the transmitter was designed to cover this range. The cam shapes were determined after the mechanism had been assembled. The trans-

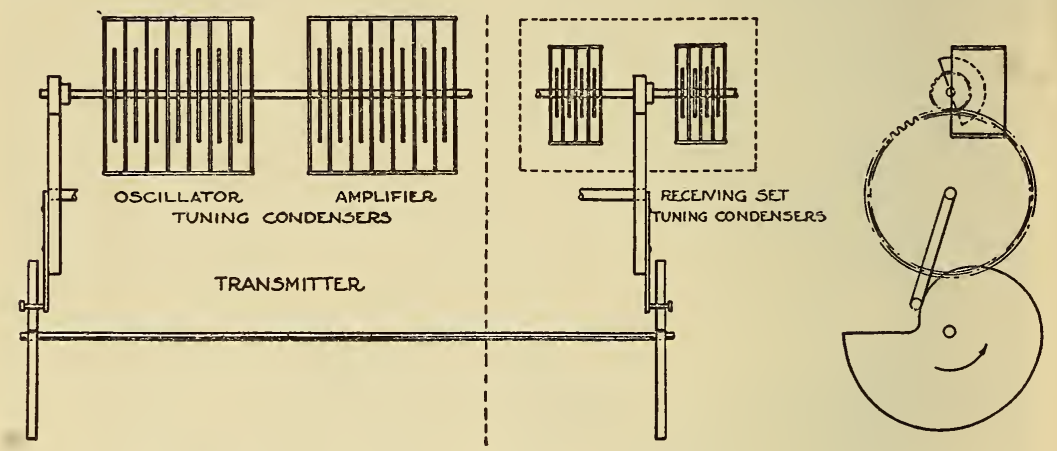

FIgURE 3.-Schemalic diagram of mechanical arrangement.

Transmitter condensers are actuated by one cam and receiving-set condensers are actuaed by another. Both cams are attached to a single shaft and are driven by a synchronous motor through a reduction gear.

mitter cam shape was determined by changing the transmitter frequency in small steps. The distance from the cam roll to the center of the cam shaft was measured for each step with a caliper. Having chosen $200 \mathrm{kc}$ per minute as the rate of change of frequency, the angular position of the cam was known for each small step. With the radius known for each angular position it was then possible to lay out this cam. In order to lay out the other cam, the receiving set was tuned to the transmitter as the frequency was varied in small steps and the distance from the cam roll to the center of the cam shaft was measured for each step. With these measurements and the known rate of rotation, this cam could be laid out. The cam was cut slightly large and then filed down to size after being installed. The tuning of the receiving set to transmitter frequency for each small step can be done conveniently while the transmitter is being pulsed. It was found advisable to keep the receiving set at low gain while tuning so that only the direct pulse was visible on the oscillograph screen. If tuning is done at high gain with reference to the sky wave pulses, inaccurate settings may be obtained at critical frequencies. 


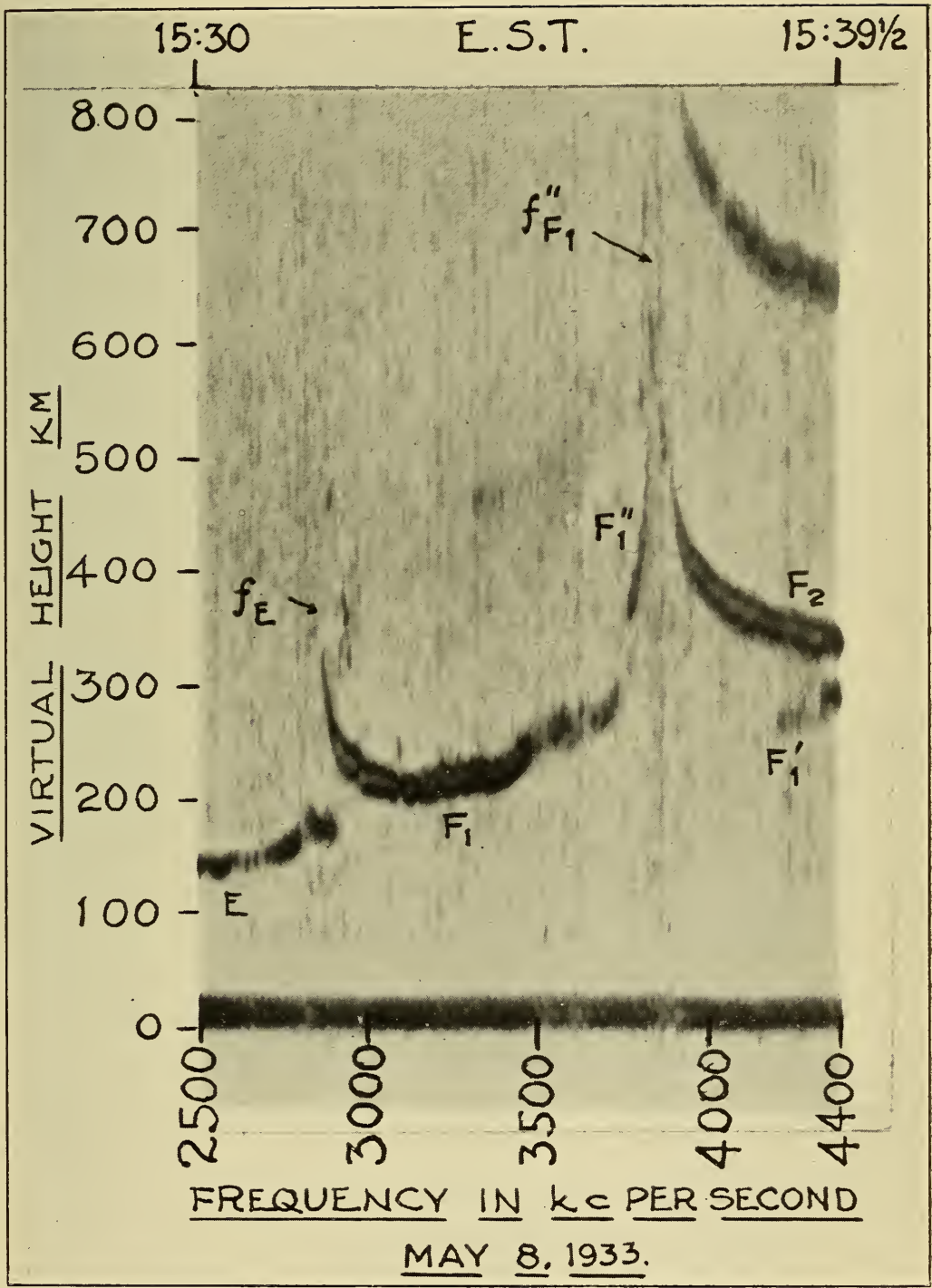

FIGURE 5.-Photograph showing type of record obtained in daytime.

$f_{E}$ denotes critical frequency for $E$ layer. $f^{\prime \prime} F 1$ denotes critical frequency for ordinary ray in $F_{1}$ layer. 


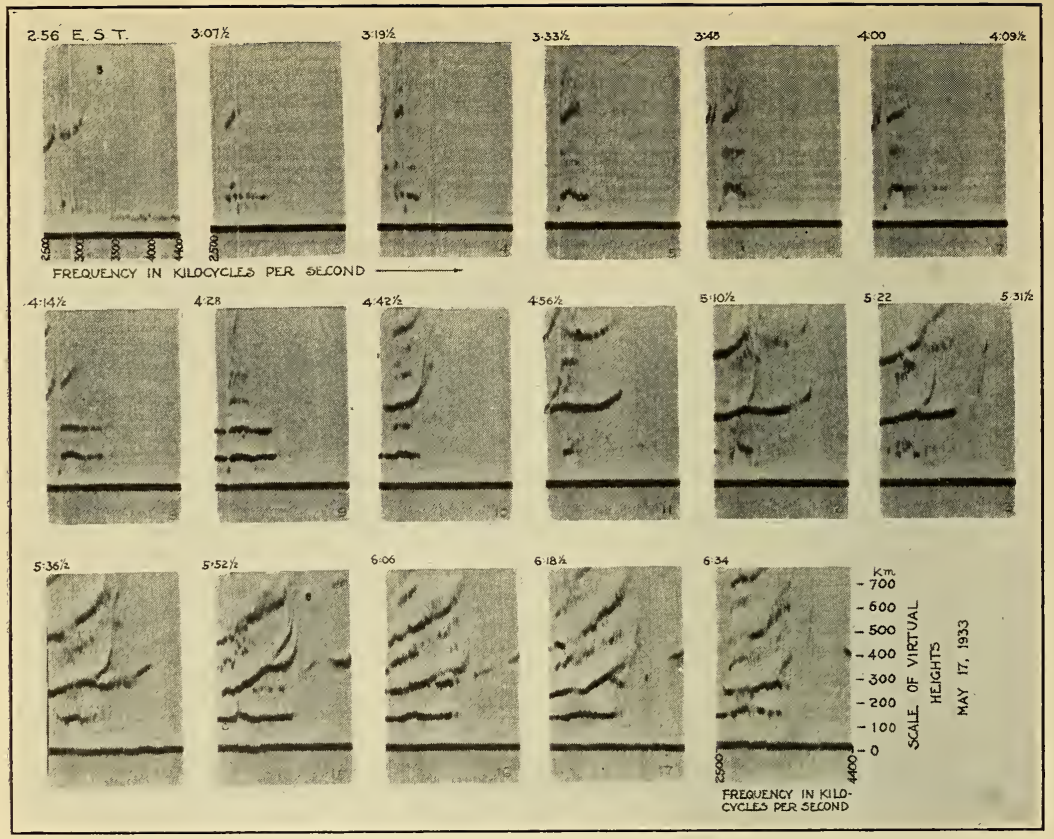

Figure 6.-Records of May $1 \%$.

Each short section represents a frequency band from 2,500 to $4,400 \mathrm{kc}$ and requires $9 \frac{1}{2} \mathrm{minutes}$. Last two records in second row show critical effects for ordinary and extraordinary rays.

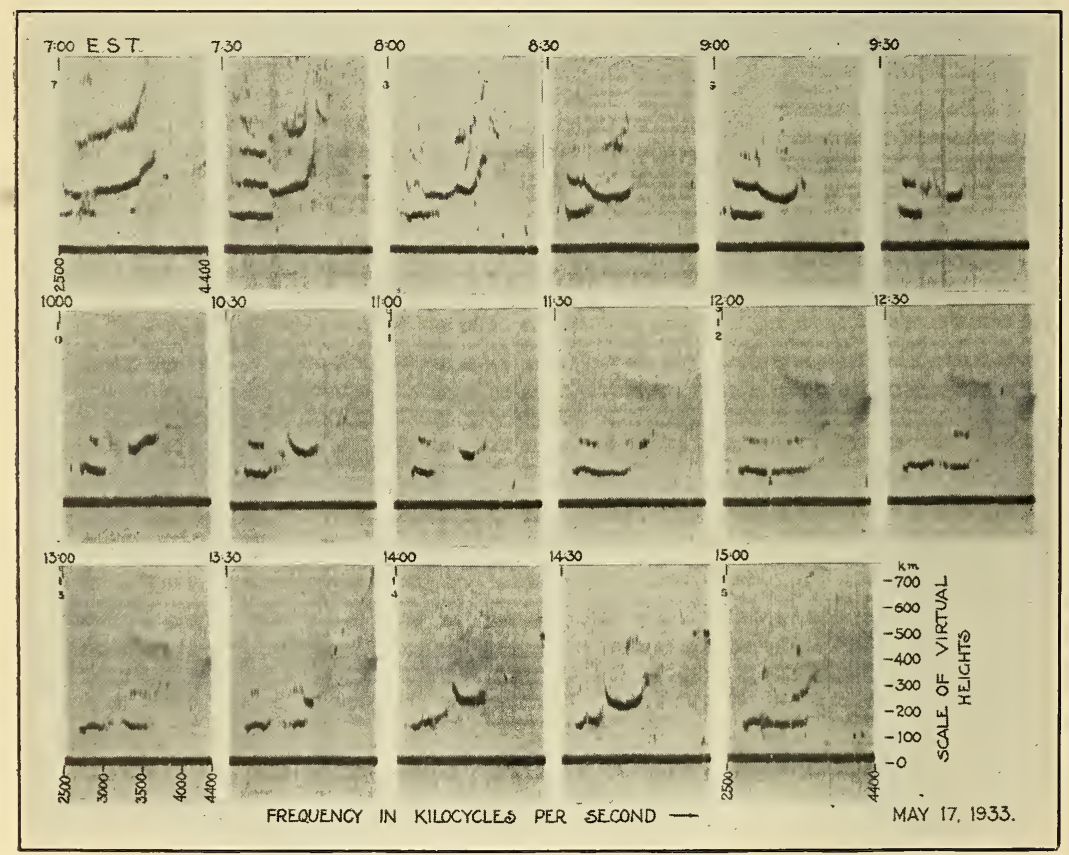

FIgURE 7.-Records for May 17 (continued).

$\mathrm{F}_{1}$ reflections were very weak during this day. 


\section{B.S. Journal of Research, RP608}

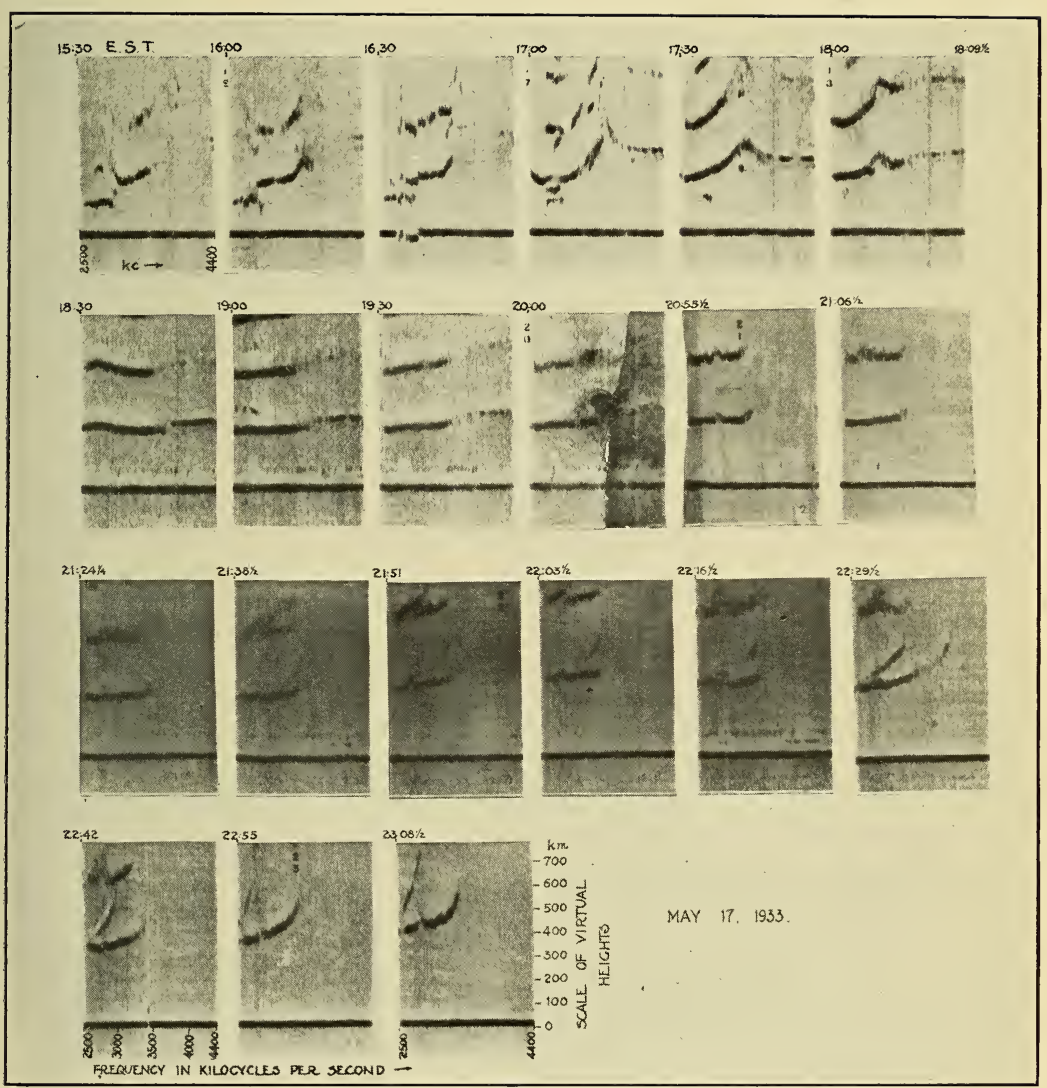

Figure 8.-Records for May 17 (continued).

Note appearance of $F_{1}$ stratification at 1700 which disappears later in evening. The ordinary and extraordinary rays become critical in this band again before midnight. 


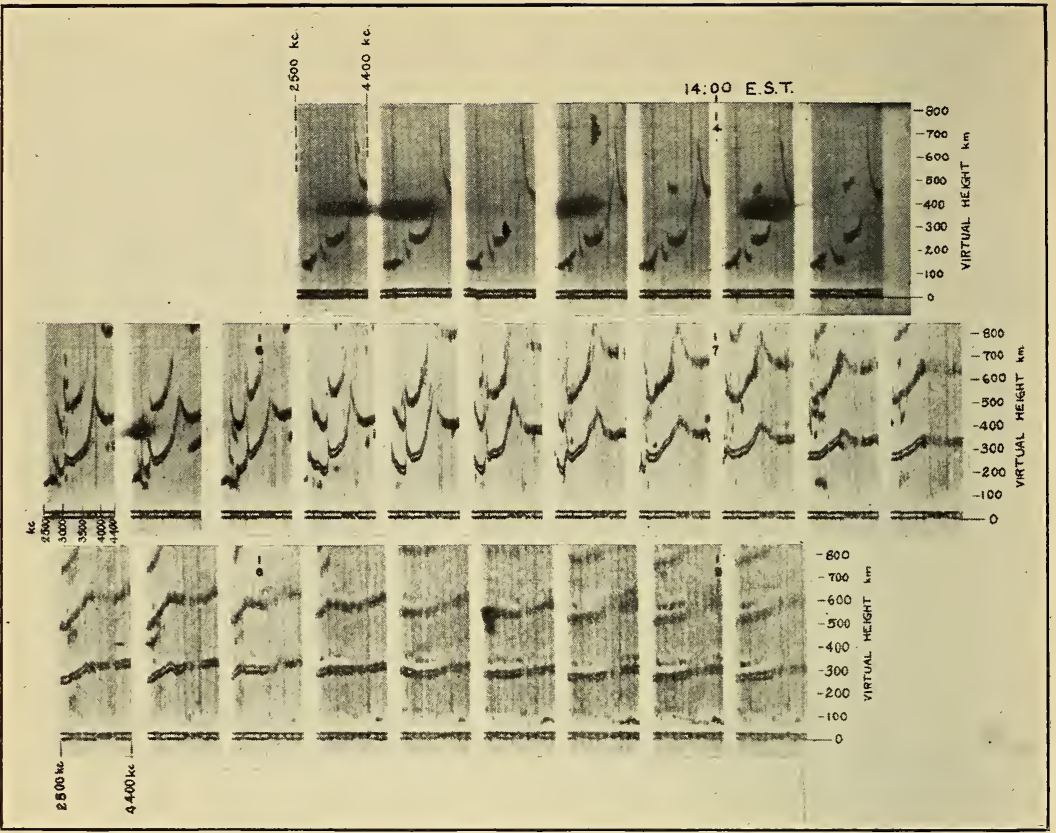

FIGURE 9.-Photograph of records taken during afternoon and evening of April 22. Note double critical effect between $\mathrm{E}$ and $F_{1}$ layer in first row.

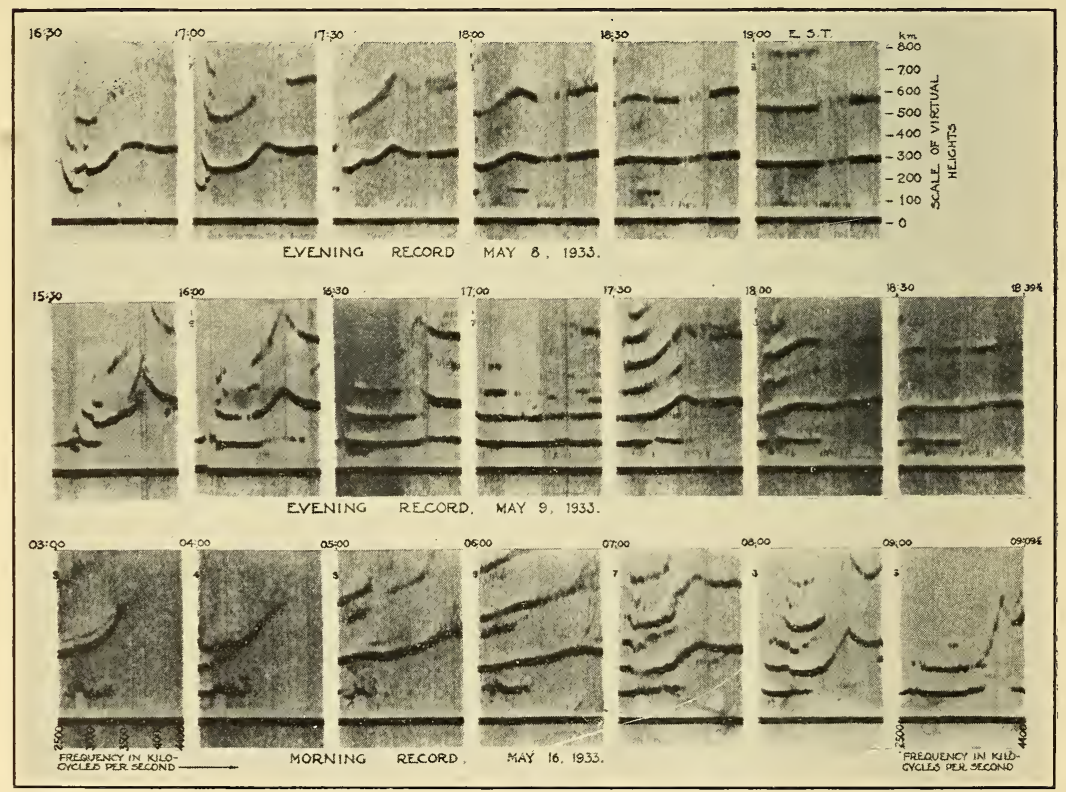

FIGURE 10.-Records showing changes during two evening runs and one morning run. Records for morning of May 16 show beginning of $F_{1}$ stratification. 
The system is adapted for sweeping automatically through the band either once each hour or each half hour. If switching is done manually at the end of each run, it is possible to sweep through the band almost six times per hour.

Figure 4 is a photograph of the preliminary arrangement of the transmitter, receiving set, and recorder.

\section{RESULTS}

The type of record obtained in the daytime is shown in figure 5 . Here the notation followed is that adopted by Kirby, Berkner, and Stuart in a paper now in preparation. The single and double prime letters indicate extraordinary and ordinary rays, respectively, in accordance with the notation of Appleton and Builder. ${ }^{6}$ Figure 5 shows the changes in virtual height as the frenquency is changed uniformly from 2,500 to $4,400 \mathrm{kc} / \mathrm{s}$ at the rate of $200 \mathrm{kc} / \mathrm{s}$ per minute. $E$ layer reflections are noted at the left coming from a virtual height of about $135 \mathrm{~km}$ for $2,500 \mathrm{kc} / \mathrm{s}$. The virtual height increases gradually as the frequency is increased to about $2,850 \mathrm{kc} / \mathrm{s}$. This is the critical frequency $\mathrm{f}_{E}$ for the $E$ layer, and long retardations occur. As frequency is increased above this point, the virtual height drops rapidly to the level of the $F_{1}$ layer. At about $3,200 \mathrm{kc} / \mathrm{s}$, the virtual height reaches a minimum of $210 \mathrm{~km}$ for the $F_{1}$ layer. As the frequency is increased the virtual height of the $F_{1}$ layer for the ordinary ray $\left(F^{\prime \prime}{ }_{1}\right)$ increases until another critical value $\mathrm{f}^{\prime \prime}{ }_{F 1}$ is reached at about $3,850 \mathrm{kc} / \mathrm{s}$ and the virtual height reaches $700 \mathrm{~km}$. This critical frequency is thought to be that for the ordinary ray as it passes through the $F_{1}$ layer. As frequency is increased still farther, reflections for this ray come from the $F_{2}$ region showing virtual heights of about 330 $\mathrm{km}$. The trace at the right marked $F_{1}^{\prime}$ is thought to be the extraordinary ray for the $F_{1}$ layer. It is usually relatively weak and frequently does not appear at all. From observations on higher frequencies, Kirby, Berkner, and Stuart have noted that this ray becomes critical at a frequency approximately $800 \mathrm{kc} / \mathrm{s}$ higher than for the ordinary ray during the daytime. It is likely that the critical frequency $\mathrm{f}_{E}$ noted for the $E$ layer is for the ordinary ray and that the extraordinary ray is absorbed. The trace in the upper right hand corner is a multiple of the $F_{2}$ trace indicating that the pulse energy has gone up to the $F_{2}$ layer and back twice. As evening approaches the stratification indicated in the $F$ region disappears and it appears to become a single layer.

Figures 6,7 , and 8 show records taken over a period of about 21 hours. Each short section of record represents the frequency band of 2,500 to $4,400 \mathrm{kc} / \mathrm{s}$ and requires $9 \frac{1}{2}$ minutes. In figure 6 weak reflections are recorded for both the $E$ and the $F$ regions until about 0415 when strong $E$ reflections appear. By 0456 , the $E$ reflections have practically disappeared and strong $F$ reflections are recorded. The records beginning at $0510 \frac{1}{2}$ and 0522 show the critical effects for the two rays. It has been suggested that the frequency separation between these two rays, when critical, should give a measure of the strength of the earth's magnetic field at the layer. ${ }^{7}$ Results during the remainder of the morning and the early afternoon should not be taken as typical. Apparently abnormally strong $E$ layer ionization

${ }^{6}$ Appleton and Builder. Proc. Phys. Soc., vol. 45, part 2, p. 208, 1933.

$7 \mathrm{~A}$ theoretical discussion of this point is now in preparation by Mr. K. A. Norton. 
was occurring at intervals and $F$ layer reflections were very weak at the higher frequencies. The absence of $F_{1}$ reflections during the middle of the day was checked by manual observations with other equipment. By 1700 (fig. 8) the $E$ critical frequency is just below $2,500 \mathrm{kc} / \mathrm{s}$ and $F$ region stratification is now in evidence. The stratification gradually becomes less pronounced and has practically disappeared by 1830 , which is 48 minutes before sunset at the ground. Critical effects for the two rays appear before midnight. The failure to record reflections between 3,500 and $4,000 \mathrm{kc} / \mathrm{s}$ at times is caused by interference from the large number of amateur stations in this band.

Figure 9 shows records taken during the afternoon and evening of April 22. The records in the first row show a double critical effect between the usual $E$ and $F_{1}$ layers, indicating another stratum, making a total of four strata at this particular time. The changes indicated at the left in the second row are complex and very sharp critical effects are noted. As evening approaches the $E$ layer critical frequency goes below $2,500 \mathrm{kc} / \mathrm{s}$ and the $F$ region stratification gradually disappears.

Figure 10 shows records taken during two evenings and one morning. The records for the evening of May 9 show the appearance of strong $E$ reflections which obscure $F$ reflections for a time. The morning records for May 16 show the beginning of the $F$ region stratification.

\section{CONCLUSION}

In this note, preliminary results have been presented with the view to indicating the possibilities offered by this method in the study of radio transmission and physical properties of the upper atmosphere. It is believed that records of the type shown give a more complete picture than it has been possible to obtain by methods previously used. It is hoped that it will be possible to continue these observations and to cover a wider band of frequencies.

Washington, June 17, 1933. 